\title{
Green Space and Its Role to Improve Social and Economic Development for a Better Quality of Life
}

\author{
Nguyen Thi Hoai TRINH ${ }^{1}$ \\ Claudiu CICEA2
}

DOI: $10.24818 / \mathrm{mer} / 2021.06-04$

\begin{abstract}
This paper aims to clarify the role of green space in improving the quality of life by a systematic review of literature. This review analyzes 45 publications to extract relevant insights. Green spaces presumably bring about many social, economic and environmental benefits to humans, thereby enhancing their life quality. Besides, to clarify the role of green spaces to improve social and economic development for a better quality of life in a particular city, the author proposes a theoretical framework and policies to promote the efficient use of green space in this regard.
\end{abstract}

KEYWORDS: economy, environment, green space, quality of life, society

JEL CLASSIFICATION: $O 18$

\section{INTRODUCTION}

Today's living world is being threatened by the serious lack of greenery; this lack causes the earth to heat up, worsens existing pollution, and deprives humans and animals of accommodation and fresh air. The rapid growth of cities poses the greatest threat to the environment, in turn damaging lives of city dwellers.

As an essential environmental asset, green space plays a vital role in humans' lives (Wolch et al., 2014). World Health Organization (WHO), with many publications and studies on the importance of green space to good living and public health, has shown that urban green spaces such as parks, sports fields, forests, lakeside forests, and gardens give people space for physical activities, relaxation, peace, and escape from hot temperatures. As a result, these spaces reduce stress and increase mental and physical health. Green spaces also contribute to improved air quality and reduced traffic noise.

In recent decades, in parallel with models of sustainable development and human development, the idea of improving the quality of urban life has been proposed and highly valued. Urban parks have social, economic, ecological roles and advantages such as aiding with mental health treatment, raising children, enhancing social inclusivity, and maintaining comfort - indicators of improvement in both quality and space enhancement of life and developing societies (Balram \& Dragićević, 2005).

This paper aims to systematically review existing literature to clarify the role that green spaces can play in improving the quality of life and have a clearer view of green space's approach in providing value to human life. The assessment also presents a basic theoretical framework to create a premise for the following studies.

\footnotetext{
1* Bucharest University of Economic Studies, hoaitrinh.hce@ gmail.com, corresponding author

${ }^{2}$ Bucharest University of Economic Studies, claudiu.cicea@man.ase.ro
} 
The paper concludes with the main ideas and policy implications to improve the quality of life by conserving and promoting green spaces, as well as making suggestions for future research directions.

\section{LITERATURE REVIEW}

In this section, we will analyze both main concepts, which represent the core of the research, namely green spaces and quality of life. Regarding green spaces, we can say that are a part of an open-space urban area, in which natural and mainly human-made forms are predominantly trees, shrubs, plants, flowers, grass, and others. They are maintained or built upon human supervision and management and are considered with relevant terms, rules, and expertise to improve citizens' living conditions, living environment, and welfare (Khansefid, 2013).

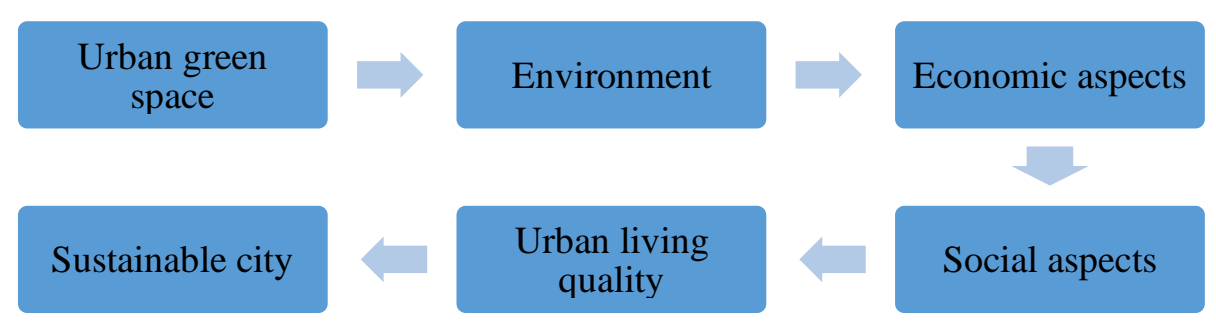

Figure 1. Model of sustainable city

Source: (Khansefid, 2013)

Urban green space is considered a term derived from urban nature conservation movements and green space planning ideas (Swanwick et al., 2003).

There is always debate and disagreement about the definition of "urban green space." Different fields have proposed different definitions from their expertise, such as urban green space, urban open space, urban garden system, and ecological garden system (Malun, 2003).

Some studies (World Health Organization, 2017) argued that green space refers to lands covered by natural or human-made vegetation in the construction and planned areas. Alternatively, in another study (Bilgili \& Ercan , 2012) defining green space from a different angle, taking into account human impacts on nature, green spaces are defined as urban areas where the conversion of natural or semi-natural ecosystems occurs in urban space under human activities. Another interesting study (Zhang, 1999), from a landscape planning and urban design perspective, defined green space as almost all areas of the city and its areas, allowing everyone to immerse themselves in nature.

According to Greenspace Scotland, green space is the "green lung" of towns and cities. Basically, "green space" is an area of vegetation in an area. The United States Environmental Protection Agency (EPA) defines green spaces as partially or entirely covered by grass, trees, shrubs, or other vegetation. These include parks, community gardens, and cemeteries.

The most crucial goal of urban growth and development is to improve the quality of life and provide welfare to citizens (Hemati et al., 2014). However, quality of life is a multidimensional concept with many different aspects. Quality of life includes nine aspects: Material well-being, Health, Political stability and security, Family life, Community life, Climate and geography, 
Job security, Political freedom, and Gender equality (The Economist, 2006). Some authors (Felce \& Jonathan , 1995) define the quality of life as the degree of total happiness, including objective and subjective assessments of physical, social and emotional development, as well as individual performance, all evaluated together in a set of individual values. According to Slaby (1990), quality of life generally refers to public health, political stability, and security of family life, social life, and job security. Another study (Harvey, 1993) considers the quality of life as closely connected with how people perform their daily routine and the relationship between their environment, choices, and behaviors.

The WHO's characterization of quality of life has six components: physical health, environmental health, psychological health, social relationships, degree of independence, and mental well-being (World Health Organisation, 1997).

Another study (Schalock \& Verdugo, 2002) found that quality of life is underpinned by eight core components, as shown in Table 1 (Galloway, Bell, Hamilton, \& Scullion, 2006).

Table 1. Core components of quality of life

\begin{tabular}{|cl|l|}
\hline \multicolumn{2}{|c|}{ Core components of quality of life } & \multicolumn{1}{|c|}{ Criteria } \\
\hline 1. Emotional happiness & Contentment, self-concept, lack of stress \\
\hline 2. $\quad$ Relations between individuals & Interactions, relationships, support \\
\hline 3. $\quad$ Material welfare & Financial status, employment, housing \\
\hline 4. Personal Development & Education, personal competence, performance \\
\hline 5. Physical health & Health, leisure, activities of daily living \\
\hline 6. Self-determination & $\begin{array}{l}\text { Autonomy/personal control, goals and personal } \\
\text { values, choices }\end{array}$ \\
\hline 7. Social inclusion & $\begin{array}{l}\text { Community integration and participation, } \\
\text { community roles, social support }\end{array}$ \\
\hline & & Human and civil rights \\
\hline
\end{tabular}

Source: (Galloway, Bell, Hamilton, \& Scullion , 2006)

Quality of life can be structurally constituted of physical, social, emotional, psychological, and physical health. Therefore, in order to achieve a better quality of life, a person's physical, social, emotional, psychological, and physical health must be significantly improved (Mensah et al., 2016).

Physical health is the "ability to participate fully, regularly, in all development-relevant activities" (Cole, 2006). A person's degree of happiness or satisfaction with life is expressed through psychological health (Felce \& Jonathan , 1995). 
Social welfare refers to healthy relationships between individuals and family members as well as the community, and material welfare that focuses on acquiring material things allows a person to act meaningfully to pursue one's goals and enjoy life (Felce \& Jonathan , 1995).

Social welfare refers to healthy relationships between individuals and family members as well as the community, and material welfare that focuses on acquiring material things allows a person to act meaningfully to pursue one's goals and enjoy life (Felce \& Jonathan, 1995).

\section{RESEARCH METHODOLOGY}

Formulating questions to guide the document review: This phase establishes the research question to capture the main problem and the purpose of the research. This practice keeps the review well-structured and focused on the topic under study. The research question is:

- What are the benefits of green spaces for improving the quality of life?

\subsection{Determine the scientific source}

This article used a bibliometric analysis method to study scientific knowledge in a particular field (articles, book chapters and conference proceedings) based on statistical tools, aiming to identify the relevant publications with the study area. We can mention that it was used in other previous papers (Cicea, Performance in public management. A research agenda with bibliometric approach, 2020).

Regarding various scientific databases in the world, the consensus of experts is that the top two databases, which are superior to the others (by the number of articles, coverage area, and prestige), are Scopus (provider - Elsevier), and Web of Science (provider - Clarivare Analytics)) However, most scientific outputs are indexed in both databases above. In order to avoid errorprone redundancy when analyzing scientific papers, the author only considers one database, which is Scopus (due to the smaller database of Scopus compared with WOS, it makes searching and analyzing faster and more focused).

\subsection{Determine the scientific literature that will be the object of the analysis}

By using the search engine of the Scopus database, the authors used the keywords "green space," "public open space," "open space," "park," "quality of life," "public health" in the title of the publications. The primary database was created to be analyzed. Afterward, the authors eliminated all deviations and outside elements (e.g., works not written in English and in 2021 - because 2021 is not a full year, only selected works, which are articles, conference proceedings, and book chapters).

\subsection{Analysis and synthesis of evidence}

After creating the database, the authors analyzed the scientific literature related to green space's impact on life quality. The analysis was performed using the Scopus database tools and the VOSViewer (Eck \& Walman, 2011). At the same time, the analysis considered several aspects, including the category and distribution of scientific studies, the temporal, and the scientific terminology.

\subsection{Identifying the main roles of green space}

The author does in-depth research about green space's role, selecting the most relevant studies on the article topic, then use the literature review method to derive the role of green space.

\section{RESULTS AND DISCUSSION}


The initial search results on Scopus showed 750 scientific bibliographies. After the screening process, there were 591 documents related to green space and human life. The analysis results are presented below in terms of different aspects.

\subsection{The category and distribution of scientific studies aspect}

Specifically, 591 documents covered 26 study areas. "Environmental science" topped the table with the highest percentage at $42.47 \%$ (251 documents), followed by "Medicine" with $32.31 \%$ (191 documents). The remaining study subjects accounting for more than $3 \%$ each are presented in the table 2 .

Table 2. Studies subjects according to Scopus

\begin{tabular}{|c|l|c|c|}
\hline No. & Subject Area & Amount & Proportion \\
\hline 1 & Environmental Science & 251 & 42.47039 \\
\hline 2 & Medicine & 191 & 32.3181 \\
\hline 3 & Social Sciences & 135 & 22.84264 \\
\hline 4 & Agricultural and Biological Sciences & 98 & 16.58206 \\
\hline 5 & Earth and Planetary Sciences & 44 & 17.52988 \\
\hline 6 & Engineering & 41 & 6.937394 \\
\hline 7 & Business, Management and Accounting & 37 & 6.260575 \\
\hline 8 & Arts and Humanities & 32 & 5.414552 \\
\hline 9 & Others & $*$ & $*$ \\
\hline
\end{tabular}

Source: Authors own conception, based on Scopus

\subsection{The temporal aspect}

Some authors (Cicea, 2020) also considered the temporal aspect in a previous paper. The figure below shown the number of studies distributed between $1914-2020$.

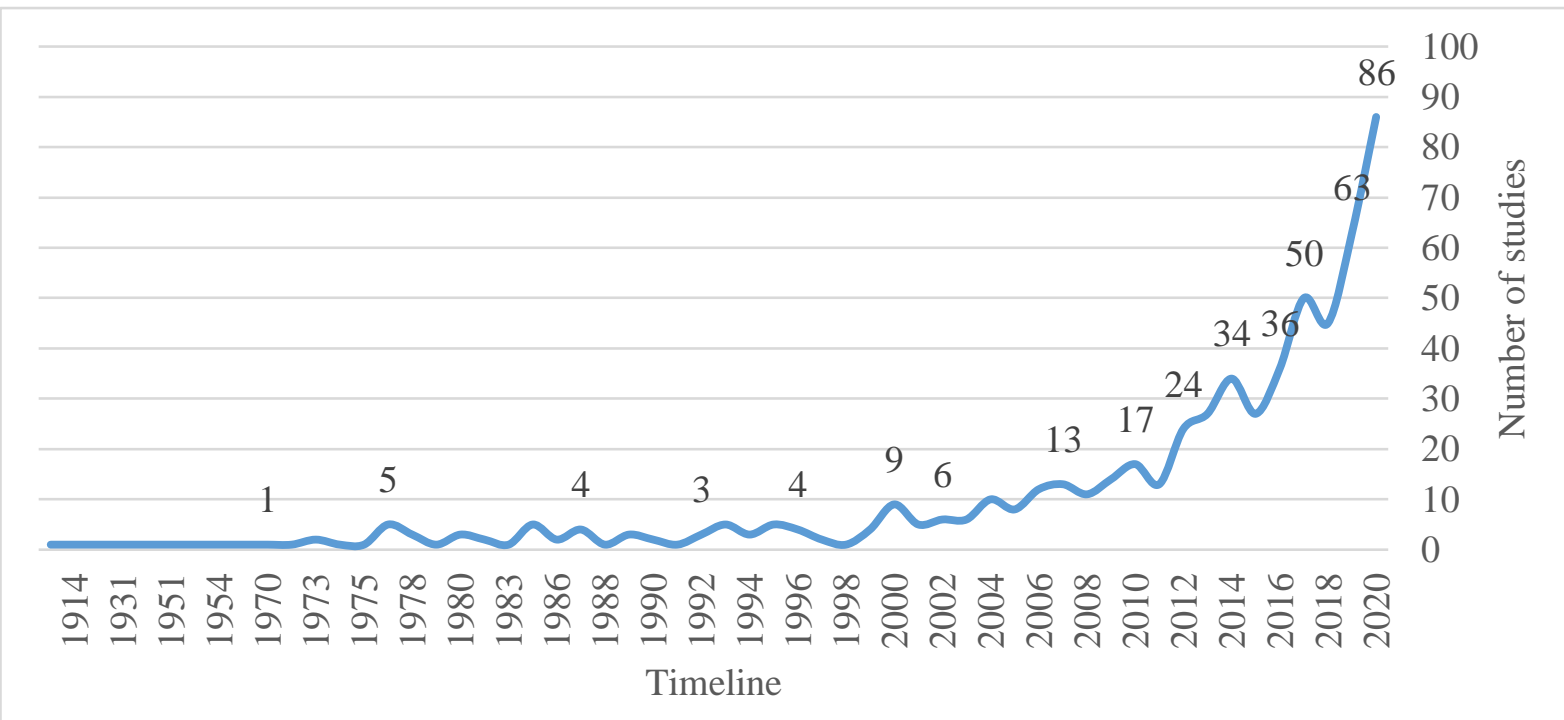

Figure 2. Temporal distribution of scientific documents

Source: Authors own conception, based on Scopus 
Over time, researchers are increasingly paying attention to the green space issue. Before the third millennium, there were only 1 to 5 scientific studies on this issue each year. Especially in 2000, there were nine studies. During the first five years of the millennium, the numbers were still between 6 and 13. However, from the second decade, there was a boom in the amount of scientific research. The year 2020 witnesses the highest number ever - 86 studies.

\subsection{The scientific terminology}

As widely explained in a previous paper (Cicea et al., 2019). The listed keywords below have the most occurrence when conducting the analysis.

Table 3. Keywords with a minimum occurrence of 10

\begin{tabular}{|c|c|c|c|c|}
\hline No. & Keyword & Frequency & Links & Cluster \\
\hline 1 & Case study & 27 & 11 & \multirow{6}{*}{1} \\
\hline 2 & China & 36 & 12 & \\
\hline 3 & Health risk & 27 & 7 & \\
\hline 4 & Health risk assessment & 16 & 6 & \\
\hline 5 & Heavy metal & 16 & 6 & \\
\hline 6 & Urban park & 26 & 13 & \\
\hline 7 & Effect & 27 & 11 & \multirow{6}{*}{2} \\
\hline 8 & Health & 156 & 14 & \\
\hline 9 & Human health & 12 & 4 & \\
\hline 10 & Research triangle park & 13 & 4 & \\
\hline 11 & USA & 13 & 6 & \\
\hline 12 & Urban green space & 43 & 12 & \\
\hline 13 & Association & 19 & 10 & \multirow{4}{*}{3} \\
\hline 14 & Green space & 91 & 14 & \\
\hline 15 & Mental health & 26 & 9 & \\
\hline 16 & Public health & 18 & 6 & \\
\hline 17 & Life history & 18 & 1 & \multirow{2}{*}{4} \\
\hline 18 & Park & 282 & 17 & \\
\hline 19 & Life & 82 & 10 & \multirow{2}{*}{5} \\
\hline 20 & Quality & 34 & 11 & \\
\hline
\end{tabular}

Source: Authors analysis, based on VOSViewer

The table 3 shows the keywords and their frequency of occurrence and shows the number of links each keyword has with other words. Keywords are divided into clusters, each with one keyword (highlighted) considered representative (due to the frequency and number of links). Only in cluster 1, the keywords are evenly distributed, but existing "Health risk" and "Health risk assessment" are similar in meaning, so the author highlighted both words.

Specifically, the status of 6 keywords based on the number of links is shown in the figure 3 . 

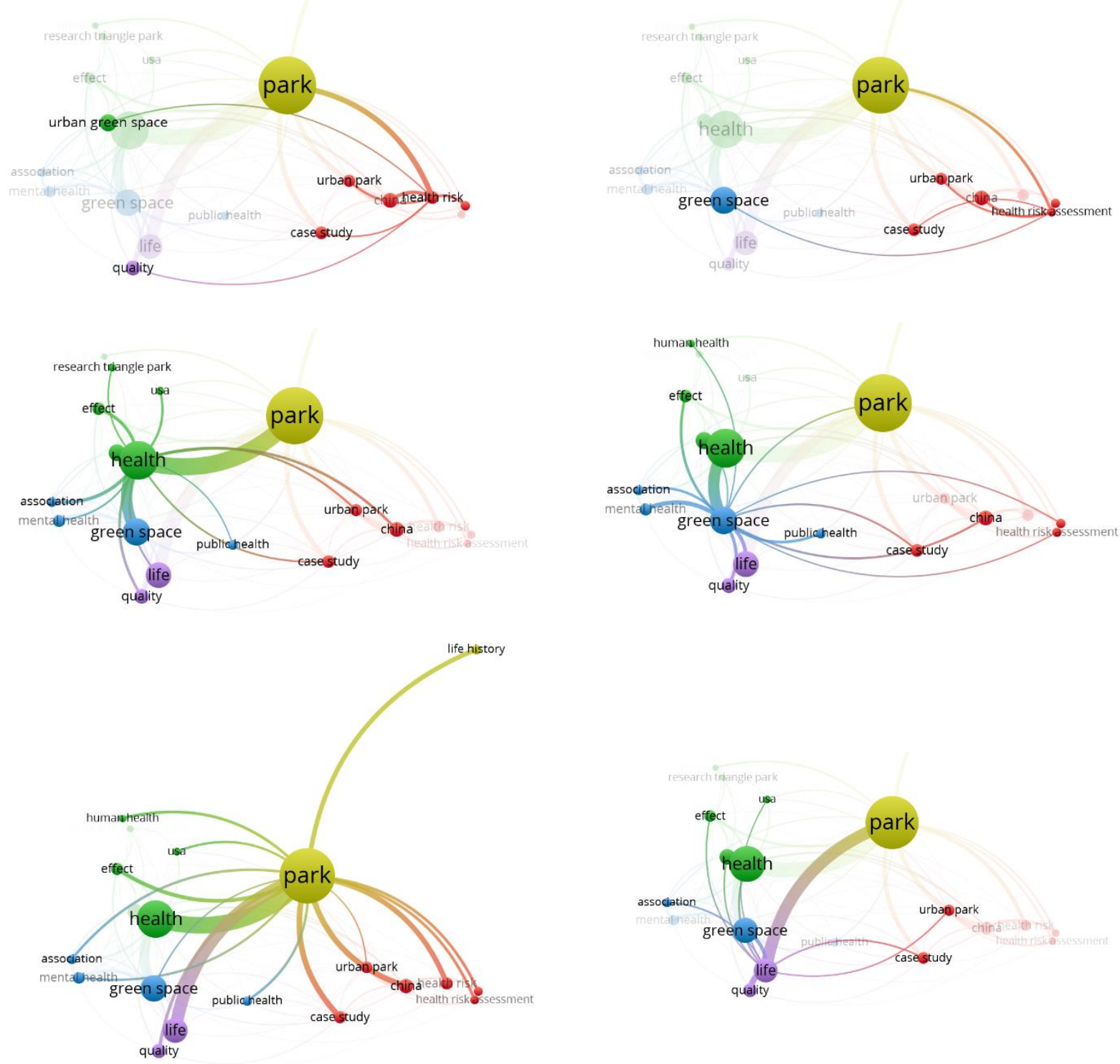

Figure 3. Keywords and their links

Source: Authors' conception based on VOSViewer

From the figure, it can be seen that the keywords are connected to a certain extent, especially "Health", "Green space," and "Life." Also, the keyword "Park" is connected to all the other keywords. With the help of VOSViewer, it is possible to know the link strength of these keywords. Details are in the table 4.

Table 4. Top keywords and their links strength

\begin{tabular}{|c|c|c|c|}
\hline No. & Keyword & Co-occurrence keyword & Link strength \\
\hline \multirow{3}{*}{1} & \multirow{3}{*}{ Park } & Health & 61 \\
\hline & & Life & 46 \\
\hline & & Health risk & 16 \\
\hline \multirow{2}{*}{2} & \multirow{2}{*}{ Health } & Park & 61 \\
\hline & & Green space & 39 \\
\hline
\end{tabular}


Nguyen Thi Hoai TRINH, Claudiu CICEA

\begin{tabular}{|c|c|c|c|}
\hline No. & Keyword & Co-occurrence keyword & Link strength \\
\hline \multirow{3}{*}{3} & \multirow{3}{*}{ Green space } & Health & 39 \\
\hline & & Mental health life & 12 \\
\hline & & Life & 10 \\
\hline \multirow{3}{*}{4} & \multirow{3}{*}{ Life } & Park & 46 \\
\hline & & Quality & 21 \\
\hline & & Green space & 10 \\
\hline 5 & Health risk & \multirow{2}{*}{ Park } & 16 \\
\hline 6 & Health risk assessment & & 7 \\
\hline \multirow{3}{*}{3} & \multirow{3}{*}{ Green space } & Health & 39 \\
\hline & & Mental health life & 12 \\
\hline & & Life & 10 \\
\hline \multirow{3}{*}{4} & \multirow{3}{*}{ Life } & Park & 46 \\
\hline & & Quality & 21 \\
\hline & & Green space & 10 \\
\hline 5 & Health risk & \multirow[b]{2}{*}{ Park } & 16 \\
\hline 6 & Health risk assessment & & 7 \\
\hline
\end{tabular}

Source: Authors analysis, based on VOSViewer

From the table 4, the keywords "Health", "Park", and "Life" are evaluated to have excellent links. In the next section, the author will evaluate the role of the green area based on the collected studies.

\subsection{Role in the environment}

Green space plays a role in improving air quality, minimizing air pollution's impact on human health and fitness. The presence of greenery in urban green spaces is related to air quality demonstration due to plants' ability to remove pollutants from the atmosphere (Nowak et al., 2006). Due to the shading effect that plants have on a surface and the cooling effect of the water they transition, they can also minimize extreme air temperature (Dimoudi \& Nikolopoulou, 2003). There is a risk of an urban heat island effect in areas with insufficient green spaces, leading to illness and death (Johnson \& Wilson, 2009). Green space covered buildings maintain lower temperatures than those with paved surfaces (due to the better absorption of heat energy by paving) (Yu \& Hien, 2006). Some studies (Gidlöf-Gunnarsson \& Öhrström, 2007) provide evidence that green spaces can help reduce noise nuisance.

The urban environment can play an essential role in providing scope for conserving species within the city (Dearborn \& Kark, 2010). Therefore, planners play a role in developing biodiversity possibilities at different scales (Alvey, 2006) through high quality, sufficiently scaled, and cohesive green spaces (Millard, 2008). Among the services provided by ecosystems for human existence are food, water, and medicine; it supports crop nutrition and pollination, flood, and erosion regulation (Mensah et al., 2016). 


\subsection{Role in social life}

Green spaces can reduce stress and increase positive feelings (Ulrich et al., 1991). In addition to the psychological benefits, there are also direct health benefits such as increased longevity (Takano et al., 2002). There are many different ways in which green spaces can positively affect well-being and well-being. Living near a park can increase physical activity levels (Kaczynski $\&$ Henderson, 2007). Some authors (Coon et al., 2011) have obtained evidence that negative emotions such as anger, mental fatigue, or sadness improve with natural exposure by a study, synthesis analysis between activities in the natural environment, and activities in the synthetic environment. At the same time, green spaces help reform and reduce violence (Chiesura, 2004).

In addition, urban green spaces can also benefit society because they can increase social cohesion and identity (Newton, 2007). Working in green spaces increases interactions between children and adults (Taylor et al., 1998). For the elderly, green spaces in the neighborhood strengthen social relationships and a sense of bond with others (Kweon et al., 1998). Natural areas with trees attract many different types of inhabitants, and dense tree plantations near buildings facilitate many group meetings (Coley et al., 1997), including people with limited social interaction (Fan et al., 2011). Besides, green spaces connect communities among local people (Kim \& Kaplan, 2004).

Another advantage is that the use of green spaces for various recreational activities can minimize the psychology of crime and violence (Mensah et al., 2016). Furthermore, green spaces' public use can increase scrutiny of neighboring properties and make them less targeted by thieves (Kuo \& Sullivan, 2001).

\subsection{Role in economy}

Green spaces and urban parks are essential stabilizing factors of the natural and human factors in today's urbanization (Esmaili, 2003). Urban green space is a part of open urban space, significant factors in the structure of urban landscapes, improving ecological conditions, providing leisure time, in which they can increase the quality of urban environments (Khalilian , 2006).

In addition to its social and physiological advantages, natural and urban green spaces can bring economic benefits to urban managers and citizens. For example, purifying the air with trees can lead to low costs of tackling pollution. Some authors (Mensah, et al., 2016) proposed that green spaces' health-promoting effect is sufficient to increase savings in healthcare costs on a national basis. The aesthetic, historical, and recreational values of urban parks can also increase urban attractiveness, tourism value, and income (Chiesura, 2004).

Green spaces help increase people's income, thereby generating revenue for governments by paying taxes and contributing to local government funds. The government then re-invests in infrastructure development such as roads, schools, electricity, and medical facilities (hospitals and clinics) to support people's lives (Mensah et al., 2016). For example, some studies (Crompton , 2001) show a positive effect of green space on property prices. Another study (Bazyl, 2009) showed that property prices are affected by neighborhoods (increase apartment prices by $4 \%$ if green spaces are within a distance of $1 \mathrm{~km}$ ). 
Thus, national health cost savings and real estate tax contributions give governments more income to invest in their economies, helping people get more money for more material for their lives (material welfare). It is an essential criterion of quality of life (Felce \& Jonathan , 1995).

\section{CONCLUSION AND DIRECTIONS FOR THE FOLLOWING RESEARCH}

The clarification of green space's role in improving life quality is systematically reviewed by the author in three aspects: environment, economy, and society. This role makes it imperative that green spaces be a priority in all sustainable development policies. The author proposes some recommendations to improve green spaces.

First of all, maintenance of environmental resources; address people's social needs to improve their well-being (social pillars); ensure efficient use and allocation of resources to achieve economic growth (economic pillar) to improve the quality of life of the people.

Secondly, in terms of society, establish and promote the role of green spaces in health institutions. Green spaces have health benefits, and green spaces help address common public health issues such as physical inactivity, depression, stress, obesity, and diabetes. Besides, green spaces should also be considered as a resource to support special education for children. Exposure to the natural environment will help children develop soft skills as well as physical health, cognitive skills, and language.

Thirdly, in economic terms, it is necessary to develop policies to promote local business growth and economic development at the community level.

This research stops at presenting a theoretical basis for green space's role in improving the quality of life. Therefore, this study has certain limitations, and above those limitations, the paper suggests some directions for future research.

First, this is a general theoretical basis so that certain adjustments may apply to each urban area. First, this is a general theoretical basis so that certain adjustments may apply to each urban area. Second, based on research concepts, future studies need to build scales for these concepts. They need to build a scale that can inherit and select from previous studies, then conduct testing to form official scales for each specific factor.

Third, future studies may test this proposed theoretical basis for a specific destination, from which the results are drawn to compare with the results from previous studies and with a theoretical basis.

\section{REFERENCES}

Alvey, A. A. (2006). Promoting and preserving biodiversity in the urban forest. Urban Forestry and Urban Greening. 5(4),195-201.

Balram, S., \& Dragićević, S. (2005). Attitudes toward urban green spaces: integrating questionnaire survey and collaborative GIS techniques to improve attitude measurements. Landscape and Urban Planning, 71(2-4), 147-162.

Bazyl, M. (2009). Hedonic price model for Warsaw housing market. Working paper 42, Department of Applied Econometrics, Warsaw School of Economics.

Bilgili, B. C., \& Ercan , G. (2012). Urban Green Space System Planning. In Ozyavuz M. (ed), Landscape Planning (pp107-122), Intechopen. 
Chiesura, A. (2004). The role of urban parks for the sustainable city. Landscape and Urban Planning, 68(1), 129-138.

Cicea , C., Marinescu, C., Albu, C., \& Balan, P. (2019). Applying Bibliometric Mapping and Clustering on Research regarding Biomass related Innovation. Proceedings of 33rd IBIMA Conference: 10-11 April , (pp. 2404-2419). Granada, Spain.

Cicea, C. (2020). Mapping the Research Agenda of Energy in Urban Areas: A Bibliometric Analysis. Theoretical and Empirical Researches in Urban Management, 15, 66-80.

Cicea, C. (2020). Performance in public management. A research agenda with bibliometric approach. Administratie si Management Public, 35, 109-123.

Cole, P. (2006). All children ready for school: Health and physical well-being. Early childhood paper briefing. Bloomington, USA: Early Childhood Center, Indiana Institute on Disability and Community.

Coley, L. R., Sullivan, W. C., \& Kuo, F. E. (1997). Where Does Community Grow?: The Social Context Created by Nature in Urban Public Housing. Environment and Behavior, 29(4), 468-494.

Coon, J., Boddy, K., Stein, K., Whear, R., Barton, J., \& Depledge, M. (2011). Does Participating in Physical Activity in Outdoor Natural Environments Have a Greater Effect on Physical and Mental Wellbeing than Physical Activity Indoors? A Systematic Review. Environmental Science and Technology, 45(5), 1761-1772.

Crompton , J. (2001). The impact of parks on property values: a review of the empirical evidence. Journal of Leisure Research, 33, 1-31.

Dearborn, D. C., \& Kark, S. (2010). Motivaciones para Conservar la Biodiversidad Urbana. Motivations for Conserving Urban Biodiversity, 24(2), 432-440.

Dimoudi, A., \& Nikolopoulou, M. (2003). Vegetation in the urban environment: Microclimatic analysis and benefits. Energy and Buildings, 35(1), 69-76.

Eck, N. v., \& Walman, L. (2011). Text mining and visualization using VOSviewer. ISSI Newsletter, 50-54.

Esmaili, S. A. (2003). Pollution Health and Environmental Standards. Iran: Naghshemehr.

Fan , Y., Das, K., \& Chen, Q. (2011). Neighborhood green, special support, physical activity and stress:. Health \& Place, 17(6), 1202-1211.

Felce, D., \& Jonathan , P. (1995). Quality of life: Its definition and measurement. Research in Developmental Disabilities, 16(1), 51-74.

Galloway, S., Bell, D., Hamilton, C., \& Scullion, A. (2006). Well-Being and Quality of Life: Measuring the Benefits of Culture and Sport - A Literature Review and Thinkpiece. Edinburgh, Scotland: Scottish Executive Social Research.

Gidlöf-Gunnarsson, A., \& Öhrström, E. (2007). Noise and well-being in urban residential environments: The potential role of perceived availability to nearby green areas. Landscape and Urban Planning, 83(2-3), 115-126.

Harvey, A. S. (1993). Quality of life and the use of time theory and measurement. Journal of Occupational Science, 1, 27-30.

Hemati, Z., Kiani, D., \& Mosavi, F. (2014). Comparison of The Quality of Life Among Patients with Idiopathic Thrombocytopenic Purpura and Healthy People in Isfahan, Iran. Iranian Journal of Blood and Cancer (IJBC), 7, 31-36.

Johnson, D. P., \& Wilson, J. S. (2009). The socio-spatial dynamics of extreme urban heat events: The case of heat-related deaths in Philadelphia. Applied Geography, 29(3), 419434.

Kaczynski, A. T., \& Henderson, K. A. (2007). Environmental correlates of physical activity: a review of evidence about parks and recreation. Leisure Sciences, 29(4), 315-354. 
Khalilian , A. (2006). Designing, programming and managing the urban green spaces appropriate with the needs of physical disable people. Collection of articles of urban management and programing conference, (p. 854).

Khansefid, M. (2013). Approaches to Urban Infrastructure Design and Delivery A Case of EastLink in Melbourne, Australia. International Federation of Landscape Architects (IFLA) 50th World Congress, 302-310.

Kim, J., \& Kaplan, R. (2004). Physical and Psychological Factors in Sense of Community: New Urbanist Kentlands and Nearby Orchard Village. Environment and Behavior, 36(3), 313-340.

Kuo, F., \& Sullivan, W. (2001). Environment and crime in the inner city: Does vegetation reduce. Environment and Behavior, 33(3), 343-367.

Kweon, B.-S., Sullivan, W. C., \& Wiley, A. R. (1998). Green Common Spaces and the Social Integration of Inner-City Older Adults. Environment and Behavior, 30(6), 832-858.

Malun, Y. (2003). Suitability Analysis of Urban Green Space System Based on GIS. MS.

Mensah, C. A., Andres , L., Upuli, P., \& Roji, A. (2016). Enhancing Quality of Life through the Lens of Green Spaces: A Systematic Review Approach. International Journal of Wellbeing, 6, 142-163. doi:https://doi.org/10.5502/ijw.v6i1.445

Millard, A. (2008). Semi-natural vegetation and its relationship to designated urban green space at the landscape scale in Leeds, UK. Landscape Ecology, 23(10), 1231-1241.

Newton, J. (2007). Wellbeing and the natural environment: a brief overview of the evidence. United Kingdom Department of Environment, Food and Rural Affairs.

Nowak, D. J., Crane, D. E., \& Stevens, J. C. (2006). Air pollution removal by urban trees and shrubs in the United States. Urban Forestry \& Urban Greening, 4(3-4), 115-123.

Schalock, R., \& Verdugo, M. (2002). Handbook on quality of life for human service practitioners. Washington DC: American Association on Mental Retardation.

Slaby, T. (1990). he standard of living, quality of life. Wiadomości Statystyczne, 6, 8-25.

Swanwick, C., Dunnett, N., \& Woolley , H. (2003). Nature, Role and Value of Green Space in Towns and Cities: An Overview. Built Environment, 94-106.

Takano, T., Nakamura, K., \& Watanabe, M. (2002). Urban residential environments and senior. J Epidemiol Community Health, 56, 913-918.

Taylor, A. F., Wiley, A., Kuo, F. E., \& Sullivan, W. C. (1998). Growing Up in the Inner City: Green Spaces as Places to Grow. Environment and Behavior, 30(1), 3-27.

The Economist. (2006). The Economist Intelligence Unit's quality-of-life index.

Trinh, N., \& Cicea, C. (2019). Budget allocation policy for public higher education in Vietnam: a short radiography and future trends. 13th International Management Coference, 13, pp. $448-456$.

Ulrich, R. S., Simons, R. F., Losito, B. D., Fiorito, E., Miles, M. A., \& Zelson, M. (1991). Stress recovery during exposure to natural and urban environments. Journal of Environmental Psychology, 11, 201-230.

Wolch, J. R., Byrne, J., \& Newell, J. P. (2014). Urban green space, public health, and environmental justice: The challenge of making cities 'just green enough'. Landscape and Urban Planning, 125, 234-244.

World Health Organisation. (1997). Measuring quality of life: The World Health Organization quality of life. Geneva, Switzerland.

World Health Organization. (2017). Urban green spaces: a brief for action. Denmark: World Health Organization Regional Office for Europe.

Yu, C., \& Hien, W. N. (2006). Thermal benefits of city parks. Energy and Buildings, 38(2), 105-120.

Zhang, Z. (1999). Quantitative evaluation of environmental benefits of urban greenland in Beijing City. Proc. IFPRA-Asia/Pacific Congress, (pp. 315-323). Hangzhou, China. 